\title{
Effects of water extracts of frass from three locust species and various plants on oviposition and embryonic development in the desert locust, Schistocerca gregaria
}

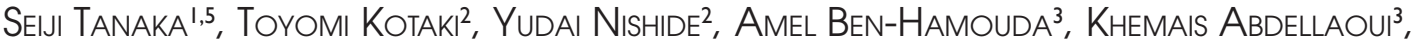 \\ Mohamed Abdallahi Bahah EbBe ${ }^{4}$, Sid OUld ElY ${ }^{4}$
}

\begin{abstract}
1 National Institute of Agro-biological Sciences at Ohawshi (NIASO), Ohwashi 1-2, Tsukuba, Ibaraki, Japan.
2 National Agriculture and Food Research Organization (NARO), Ohwashi 1-2, Tsukuba, Ibaraki, Japan.

3 High Agronomic Institute of Chott-Mariem, University of Sousse, Tunisia.

4 National Locust Control Center (NLCC); Nouakchott, Mauritania.

5 Matsushiro 1-20-19, Tsukuba, Ibaraki 305-0035, Japan.
\end{abstract}

Corresponding author: Seiji Tanaka (stanaka117@yahoo.co.jp)

Academic editor: Michel Lecoq | Received 19 March 2019 | Accepted 20 May 2019 | Published 2 October 2019

http://zoobank.org/23DA3998-23B4-4344-8A2F-8A6672981244

Citation: Tanaka S, Kotaki T, Nishide Y, Ben-Hamouda A, Abdellaoui K, Ebbe MAB, Ely SO (2019) Effects of water extracts of frass from three locust species and various plants on oviposition and embryonic development in the desert locust, Schistocerca gregaria. Journal of Orthoptera Research 28(2): 195-204. https://doi.org/10.3897/jor.28.34665

\begin{abstract}
The water extract of desert locust, Schistocerca gregaria, frass collected in the wild had an oviposition inhibitory (OI) effect when mixed with sand and presented to adults. Likewise, the leaves of six plant species, as well as frass produced by desert locusts fed with these plants, exerted OI effects when compared with the control sand wetted with water alone. In general, frass extracts had a greater OI effect than the extracts of leaves. The OI effect was also observed when adult desert locusts were exposed to extracts of frass produced by two other locusts, the Bombay locust, Nomadacris succincta, and the migratory locust, Locusta migratoria, fed with rescue grass, Bromus catharticus. Among the three species of locust, desert locust and migratory locust frass exerted a greater OI effect than Bombay locust frass. Frass samples extracted with hot and cool water produced similarly high OI effects, indicating that bacterial involvement during extraction is unlikely. Hatching rates of desert locusts were significantly reduced by extracts of all of the above mentioned frass when the extracts were mixed with sand and used to incubate the eggs. In contrast, the lethal effects of leaf extracts on the hatching rates varied depending on the plant species. The embryos became deformed within four days when three-day-old eggs were incubated in sand containing frass extracts from desert locusts fed with rescue grass, whereas no apparent morphological changes were observed when seven-day-old eggs were similarly tested, although their hatching rate was significantly reduced.
\end{abstract}

\section{Keywords}

behavior, choice test, egg hatching, oviposition inhibitory effect, plague locust

\section{Introduction}

The desert locust, Schistocerca gregaria, is potentially the most destructive insect pest in the world. During the last major desert locust outbreak in 2003-2004, eight million people in the
Sahel were affected, and crop losses caused by the locust infestation amounted to $80-100 \%$ of the expected yields (Brader et al. 2006). At low population densities, the nymphs of this species tend to avoid one another and seldom cause damage to agricultural crops. Desert locusts are relatively sedentary, and adults live solitary lives except during the mating period. However, during outbreaks, desert locusts move in bands or swarms and eat host plants voraciously, causing serious damage to agricultural crops (Uvarov 1966, 1977, Pener 1991, Pener and Simpson 2009). One of the characteristics that enables desert locust populations to grow so quickly is a high reproductive potential, and female adults frequently produce egg pods, each containing 65-75 eggs (Uvarov 1966).

The oviposition behavior and activity of acridid species are greatly influenced by soil properties such as water content (Norris 1968, Ji et al. 2007), pH (Ji et al. 2007), and chemical composition (Woodrow 1965a, b, Norris 1968, Newland and Yates 2008, Woodman 2017). Recently, Tanaka and Sugahara (2017) observed that adult female desert locusts kept in their rearing cages for several days avoided laying egg pods in old sand and demonstrated that locust frass and rescue grass, Bromus catharticus, leaves fed as feed contained one or more factors inhibiting oviposition. These oviposition inhibitory (OI) factors are water-soluble and heat-stable. Water extracts of frass also inhibited embryonic development of this locust when mixed with sand and used to incubate eggs. It is not known whether the factors inhibiting oviposition and embryonic development are the same or not, because chemical identification of the factors has not been performed. It is also not clear whether the OI effect and lethal effect on embryos are present in frass produced by locusts in the wild, or only by locusts in the laboratory. In this study, we addressed the following questions: 1) Does frass produced by locusts in the wild exert OI effects? 2) Does frass produced by other locust species exert OI effects on 
desert locusts? 3) Does frass produced by desert locusts after feeding on other plants exert an OI effect on desert locusts? 4) Is there bacterial involvement in the production of OI effects? 5) How do these frass and plant extracts affect embryonic development in desert locusts? This paper reports results obtained in relation to these questions and discusses their significance.

\section{Materials and methods}

Insects and plants. - The desert locust colony used in this study was originally collected in Niger in 2004 by Prof. H. J. Ferenz, and nymphs and adults were maintained in groups as previously described (Tanaka and Sugahara 2017). The migratory locust, Locusta migratoria, and the Bombay locust, Nomadacris succincta (also known as Patanga succincta), were collected in 2016 on MinamiDaito Island, Okinawa, Japan. Desert locusts were fed leaves of rescue grass (Bromus catharticus, BC), orchard grass (Dactylis glomerata, DG), sorghum (Sorghum bicolor, SB), Japanese mustard spinach (Brassica rapa var. perviridis, BR), romaine lettuce (Lactuca sativa var. longifolia, LS), and cabbage (Brassica oleracea var. capitata, BO), depending on the season. Migratory locusts were supplied with leaves of rescue grass, orchard grass, sorghum, or silver grass (Miscanthus sinensis, MS). Wheat bran was also constantly supplied. Adult Bombay locusts were reared on leaves of rescue grass.

The plants supplied as feed were grown at research plots of the National Institute of Agro-biological Sciences at Ohwashi (NIASO) and the National Agriculture and Food Research Organization (NARO), with the exception of the silver grass, which was collected in the field, and the romaine lettuce and cabbage, which were purchased from supermarkets.

Sample preparation and assay method.-The frass and cut leaves $\left(1-2 \mathrm{~cm}^{2}\right)$ used in the experiments were dried at a relative humidity of $10-40 \%$ for three days in the rearing room of NIASO. The frass used in the experiments were collected in the Tsukuba laboratory, except for the frass obtained from desert locusts reared on romaine lettuce at the High Agronomic Institute of Chott Mariem in Tunisia in 2016, and the frass collected under umbrella thorn trees, Acacia tortilis, at Boulenoir (21 $\left.{ }^{\circ} 14^{\prime} 23^{\prime \prime} \mathrm{N}, 16^{\circ} 34^{\prime} 26^{\prime \prime} \mathrm{W}\right)$ and Soueissiya $\left(21^{\circ} 16^{\prime} 35^{\prime \prime} \mathrm{N}, 16^{\circ} 44^{\prime} 55^{\prime \prime} \mathrm{W}\right)$ in Nouadhibou, Mauritania, in 2016 and 2017, respectively.

Each frass or leaf sample (30 g in dry weight) was soaked in water $(300 \mathrm{ml})$ overnight at room temperature, and the solution was filtered according to previously described methods (Tanaka and Sugahara 2017). In brief, $55 \mathrm{ml}$ of the extract solution was mixed with $270 \mathrm{~g}$ of sterilized sand in a plastic cup, which was presented to sexually mature locusts in a wooden-framed cage (42 $\times 22 \times 42 \mathrm{~cm}$ ) covered with nylon screens. A cup containing sand wetted with water alone was used as a control.

The number of ovipositing females in cages varied from 20 to $>50$, depending on age, and thus the number of egg pods laid varied from one experiment to another. The holes made by adult females and egg pods laid were counted daily, and the egg pods laid in the sand were removed. After removing the egg pods, the sand surface of each cup was cleaned and flattened. This procedure was repeated until a total of at least 20 egg pods were collected except for treatments in which sexually mature locusts dug many holes but laid only a few eggs into any sand cup at least for 4 days. Because ovipositing holes are easily filled when the sand is dry, the sand surface was sprayed with water every day. In this study, daily numbers of egg pods laid and ovipositing holes observed were compared between treatments. To obtain frass from locusts fed with various plants, the locusts were fed each plant for at least two days before collecting test frass for experiments.

To determine whether the OI factor was a result of bacterial activity during extraction, frass samples (30 g in dry weight) from desert locusts fed with $B$. catharticus were soaked in boiling water $(300 \mathrm{ml})$ in a water bath for $3 \mathrm{~min}$, and the solution was filtered as described above. After cooling for $7 \mathrm{~min}$, the filtrated solution (hot water extract) was mixed with sterilized sand as described above. For comparison, another set of frass samples was soaked in water $(300 \mathrm{ml})$ at room temperature for $10 \mathrm{~min}$, and the solution was filtered and mixed with sand (cool water extract). Three sand cups containing hot water extract, cool water extract, and water were presented to locusts in the same cage and the numbers of egg pods laid and holes were recorded daily.

Effects of frass and leaf extracts on egg hatching rates. - Egg pods were first incubated in clean sand in vinyl cups (diameter, $3 \mathrm{~cm}$; height, $4 \mathrm{~cm}$ ) with a lid, and egg pods were usually incubated in five groups of 20 eggs. Egg pods were buried as a mass in the test sand or clean sand on days one, three, or seven. Egg pods were incubated at $30^{\circ} \mathrm{C}$ under constant illumination and checked for hatching every day until no more hatching was observed.

Measurements of egg widths and embryonic antennal lengths.-Maximum egg widths were measured for eggs incubated at $30^{\circ} \mathrm{C}$ using an ocular micrometer installed in a binocular microscope. Embryonic antennal lengths were similarly measured after 6-11 eggs were fixed in water at $90-100^{\circ} \mathrm{C}$ for $10 \mathrm{~min}$ and were subsequently dissected.

Data analyses. - The numbers of egg pods and oviposition holes were analyzed with a t-test or Tukey's multiple range test after analysis of variance (ANOVA) using a statistics service available at http://www.gen-info.osaka-u.ac.jp/MEPHAS/kaiseki.html. The hatching percentages were analyzed with the generalized linear mixed model (GLMM), which was calculated by the function "lmer" of the program package lme4 using the software R version 3.4.2 (R Development Core Team 2018).

\section{Results}

OI effects of water extracts of desert locust frass collected under umbrella thorn trees in Mauritania._-Extracts of the two desert locust frass samples collected underneath umbrella thorn trees in Mauritania in 2016 and 2017 had similar effects on oviposition. Few or no egg pods were laid on average in the sand treated with frass extracts, whereas more than 5 pods were laid on average into the control sand kept in the same cages, and these differences were statistically significant (Fig. 1A, B; $t=-5.01, d f=13, p=0.001$ and $\mathrm{t}=-6.21, \mathrm{df}=10, \mathrm{p}=0.001$ for samples 1 and 2 ). In contrast, no significant difference was observed in the mean number of holes dug in each pair of cups (Fig. 1C, D; t-test, $p=0.08$ and 0.14 for samples 1 and 2).

OI effects of water extracts of frass produced by locusts fed with romaine lettuce. - High OI activity was observed in extracts of frass produced by desert locusts fed with romaine lettuce in Tunisia. No egg pod was laid in the cups containing the extracts, whereas a daily average of $6.3 \mathrm{egg}$ pods (94 pods in total) were laid in the control cups $(\mathrm{t}=-8.12, \mathrm{df}=14, \mathrm{p}<0.001$; Fig. $2 \mathrm{~A})$. The number of holes observed was similar between the treated and control cups (t-test, $\mathrm{p}=0.27, \mathrm{df}=14$; Fig. 2B). 


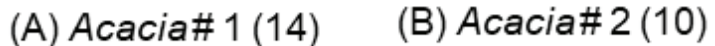

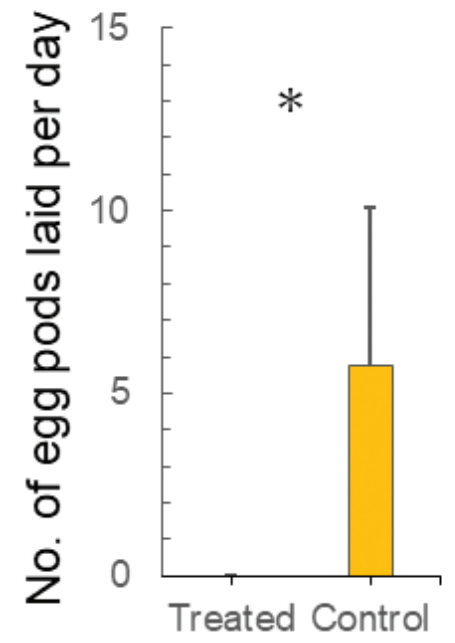

15

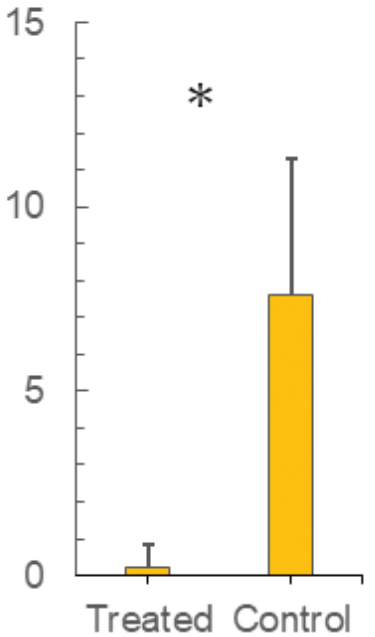

(C) Acacia\# 1 (14)

(D) Acacia\# 2 (10)

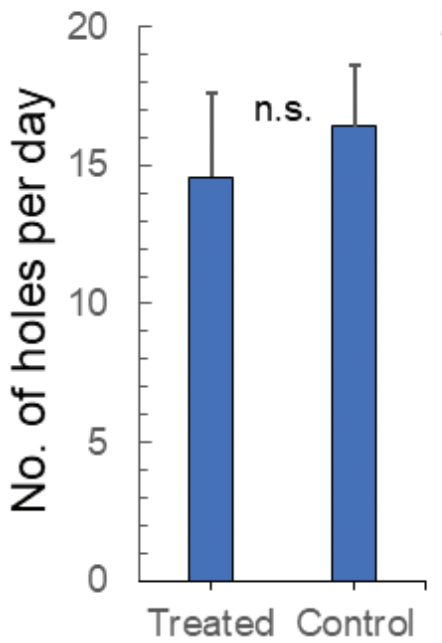

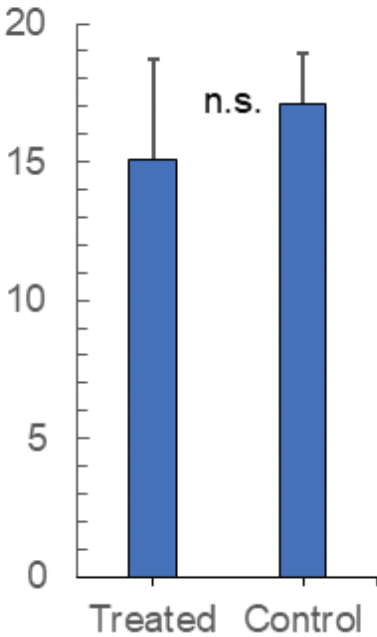

Fig. 1. Effects of water extracts of desert locust frass collected under umbrella thorn trees in the Mauritanian desert on the number of A., B. Egg pods laid, and C., D. Holes dug by adult female desert locusts presented with extracts mixed with sand. Frass were collected at sites \#1 and \#2 in 2016 and 2017, respectively. Two cups containing frass extracts (treated) and water (control) were simultaneously presented to locusts in each of two locust cages for seven or five days, and the data were combined. Numbers in parentheses indicate the total numbers of days observed. Bars on histograms indicate one standard deviation. Asterisks indicate a significant difference at the $5 \%$ level with a t-test. n.s. indicates no significant difference.

(A)

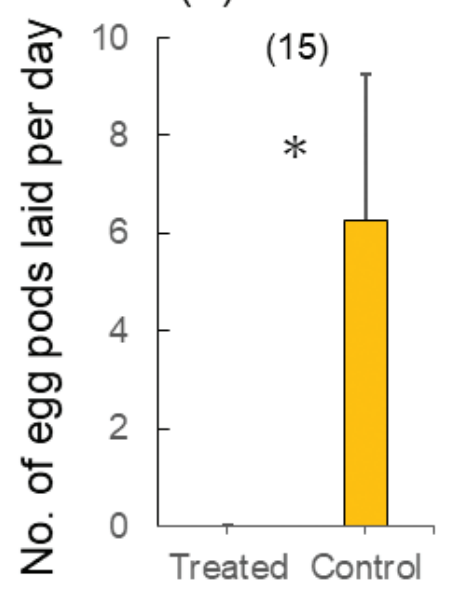

(B)

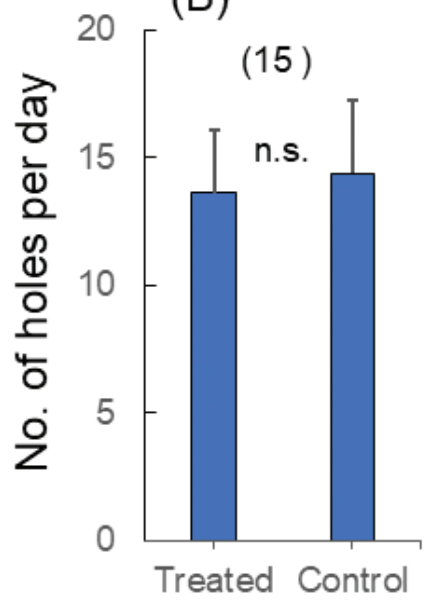

Fig. 2. Effects of water extracts of frass obtained from lab-reared desert locust fed with romaine lettuce in Tunisia on the number of A. Egg pods laid and B. Holes dug by adult female desert locusts presented with sand mixed with frass extracts. Two cups containing frass extracts (treated) and water (control) were simultaneously presented to locusts in each of two locust cages for seven or eight days, and the data were combined. Numbers in parentheses indicate the total numbers of days observed. Asterisks indicate a significant difference at the $5 \%$ level with a t-test. n.s. indicates no significant difference.

OI effect of water extracts of frass produced by desert locusts fed with various plants. - Fig. 3 illustrates the effects of extracts of leaves and frass produced by desert locusts that were fed with six different plants on oviposition. When three cups containing leaf extract, frass extract, and water were presented under choice, desert locusts laid egg pods mainly into the control cups, and only a few or no

egg pods were deposited into the cups containing extracts of frass and leaves irrespective of the plant species used. A comparison of oviposition activity between cups containing water (control) and frass extract (Suppl. material 1: Fig. S1) or leaf extract (Suppl. material 2: Fig. S2) was also performed. The results indicated that locusts laid few egg pods into the cups containing frass or leaf extracts, and laid egg pods almost exclusively into the control cups irrespective of the plant species used. These results indicate that all plants and frass tested exerted OI effects.

The OI effects were compared between the extracts of frass and leaves. In this experiment, no water cup was included because, as shown in Fig. 3, locusts given a choice laid almost exclusively into the water sand cup. Significant differences were observed in the number of egg pods between the two treatments for orchard grass, romaine lettuce, and silver grass (Fig. 4A, D, F), whereas no significant differences were observed for cabbage, sorghum, and Japanese mustard spinach (Fig. 4B, C, E). In these experiments, desert locusts laid only small numbers of egg pods overall, but they dug 50-123 holes during the test periods, indicating that digging activity was high, but oviposition was strongly repressed. In general, the OI effect was stronger for the frass extracts than for the leaf extracts.

OI effects of frass produced by other acridid species. - Frass obtained from rescue grass-fed Bombay locusts and migratory locusts exerted OI effects when the water extracts were mixed with sand and presented to adult desert locusts together with control sand wetted with water alone. In both experiments, when desert locusts were exposed to extracts of frass from the two locusts (Bombay and migratory locusts), few or no egg pods were laid in the treated sand, whereas approximately five egg pods were laid daily in the control sand (Fig. 5A, C). In contrast, no significant difference was observed in the mean number of holes between the treated and control sand cups in both experiments $(\mathrm{t}=-1.09, \mathrm{df}=28, \mathrm{p}=$ 0.28 for Bombay locusts and $\mathrm{t}=1.73, \mathrm{df}=18, \mathrm{p}=0.64$ for migratory locusts, Fig. 5B, D). These results indicate that frass from both 


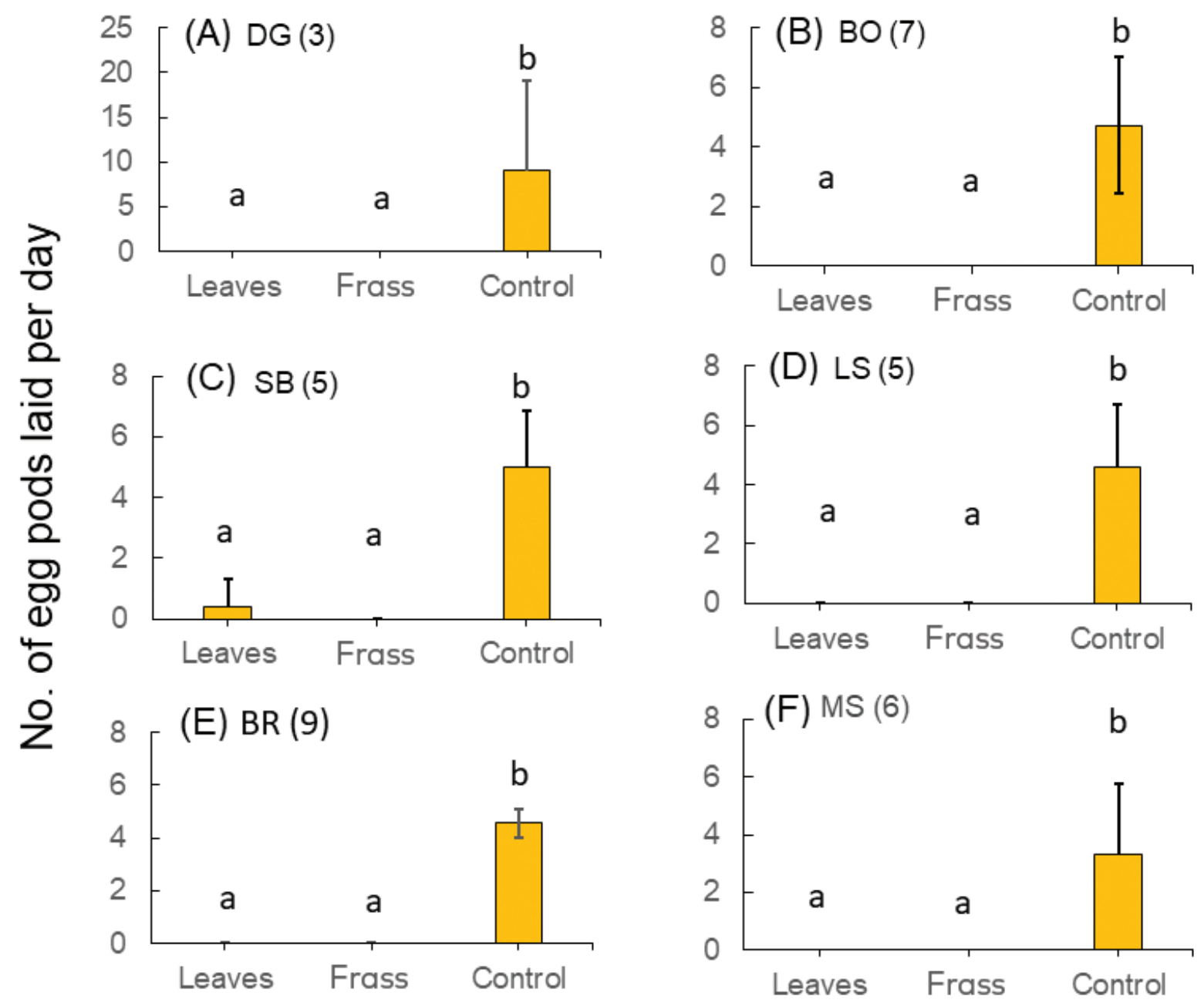

Fig. 3. Effects of water extracts of leaves of various plants and desert locust frass collected after locusts fed on these plants on the numbers of egg pods laid by adult female desert locusts presented with sand mixed with extracts. Sand wetted with water was also presented as a control. Three cups containing leaf, frass extract, and water (control) were simultaneously presented to locusts in one (A, C, D) or two locust cages (B, E, F) for three to five days, and the data were combined in (B), (E), and (F). Numbers in parentheses indicate the total numbers of days observed. Bars on histograms indicate one standard deviation. Different letters in each panel indicate significant differences at the 5\% level with Tukey's multiple comparison test. DG, Dactylis glomerata (orchard grass); BO, Brassica oleracea var. capitata (cabbage); SB, Sorghum bicolor (sorghum); LS, Lactuca sativa var. longifolia (romaine lettuce); BR, Brassica rapa var. perviridis (Japanese mustard spinach); MS, Miscanthus sinensis (silver grass).

Bombay locusts and migratory locusts exerted OI effects on desert locusts but did not affect digging activity.

When water extracts of frass produced by the three locust species (desert, Bombay, and migratory locusts) were mixed with sand and presented to adult desert locusts simultaneously, the number of egg pods laid per day was significantly lower in treatments using the frass extracts from desert locusts and migratory locusts than in treatments using frass extracts from Bombay locusts (Fig. 6A; Tukey's multiple test, $\mathrm{df}=18, \mathrm{p}<0.05$ in both experiments), whereas no significant differences were observed in the numbers of holes dug by desert locusts exposed to frass extracts from the three locust species (Fig. 6B; ANOVA, $F$ $=2.16, \mathrm{df}=2,18, \mathrm{p}=0.14$ and $F=0.88, \mathrm{df}=2,18, \mathrm{p}=0.92$ for light and dark histograms).

OI effects of hot and cool water extracts of frass of desert locusts fed with rescue grass. - Desert locusts laid no egg pod into sand cups containing hot and cool water extracts during the 4-day observation period and laid a daily average of 6 egg pods into a sand cup containing water (Fig. 7A), indicating that the OI factor was extracted with both hot and cool water. In contrast, no significant difference was observed in the number of holes made per day among the three cups (Fig. 7B, ANOVA, $F=0.19$, $\mathrm{p}=0.83, \mathrm{df}=2,9)$.

Effects of water extracts of frass and plants on desert locust egg hatching rates. - Water extracts of frass collected under umbrella thorn trees had a different effect on desert locust egg hatching rates than the control treatment did. The desert locust eggs treated with extracts of the frass sample collected in 2016 had a significantly lower hatching rate than the control eggs (Table $1 \mathrm{~A}, \mathrm{GLMM}, \mathrm{p}<0.05$ ), whereas those treated with extracts of the frass sample collected in 2017 had a similar hatching rate to that of the control eggs (Table 1A, GLMM, p > 0.05). Exposing desert locust eggs to extracts of frass collected from locusts fed with different test plants including romaine lettuce, orchard grass, sorghum, silver grass, 


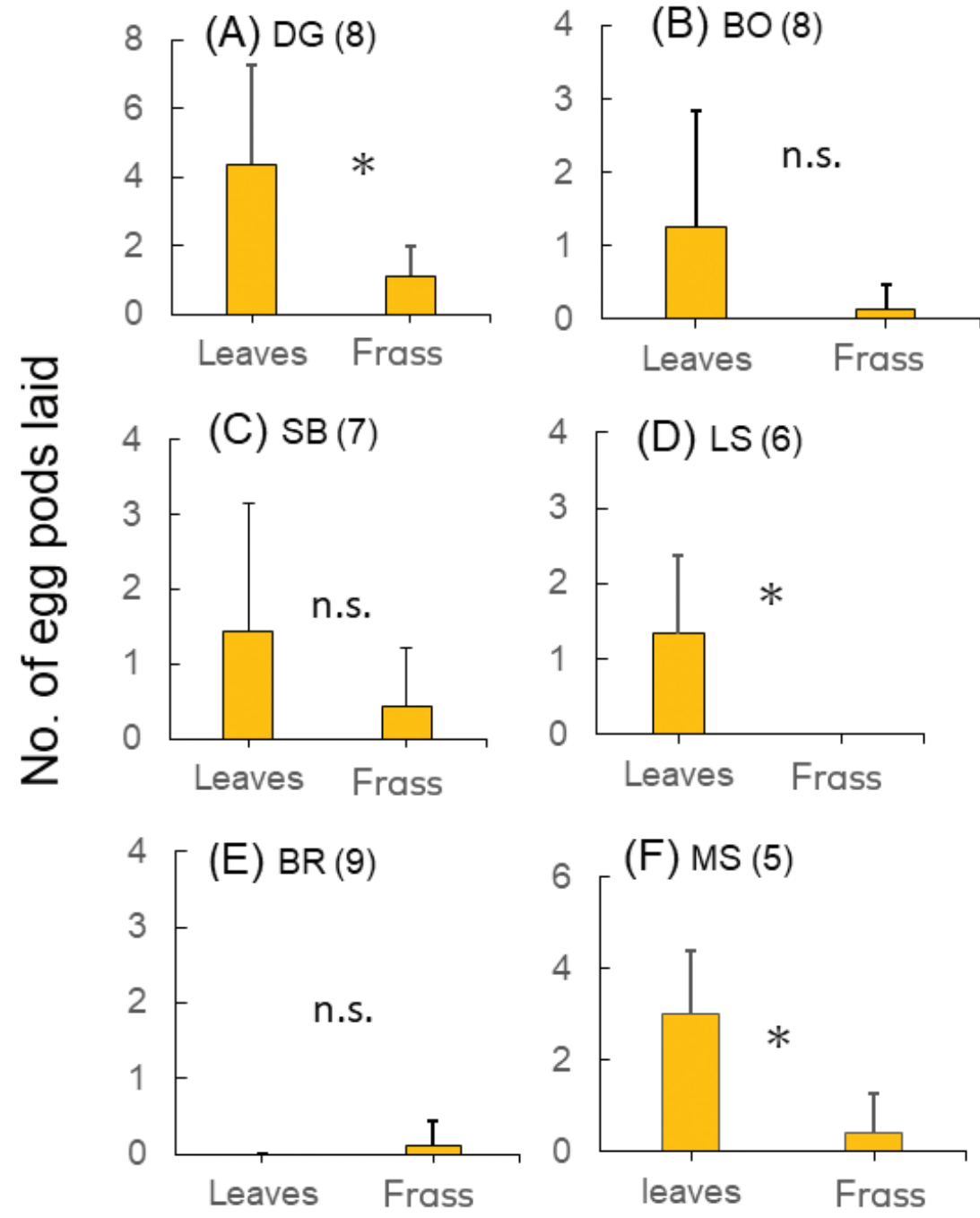

Fig. 4. Effects of water extracts of leaves of various plants and desert locust frass after locusts fed on these plants on the numbers of egg pods laid when extracts were mixed with sand and presented to adult female desert locusts. Two cups containing leaf and frass extracts were simultaneously presented to locusts in each of two locust cages for three to five days, and the data were combined. Numbers in parentheses indicate the total numbers of days observed. Bars on histograms indicate one standard deviation. Asterisks indicate significant differences at the $5 \%$ level with a t-test. n.s. indicates no significant difference. DG, Dactylis glomerata (orchard grass); BO, Brassica oleracea var. capitata (cabbage); SB, Sorghum bicolor (sorghum); LS, Lactuca sativa var. longifolia (romaine lettuce); BR, Brassica rapa var. perviridis (Japanese mustard spinach); MS, Miscanthus sinensis (silver grass).

Japanese mustard spinach, and cabbage resulted in significantly lower hatching rates than exposing eggs to the control treatment (Table 1B-G, GLMM, p < 0.05). Water extracts of different plants had different effects on desert locust egg hatching rates, depending on the species. Extracts of leaves of orchard grass, sorghum, and silver grass did not significantly affect egg hatching rates compared to the control eggs (Table 1I-K, GLMM, p > 0.05), whereas extracts of leaves of romaine lettuce, Japanese mustard spinach, and cabbage significantly reduced egg hatching rates (Table $1 \mathrm{H}$, L, M, GLMM, p < 0.05).

Effects of water extracts of frass produced by Bombay locusts and migratory locusts on desert locust egg hatching rates. - Incubating eggs in sand wetted with frass extracts from Bombay locusts and migratory locusts significantly reduced the hatching rate of desert locust eggs compared to the control treatment, i.e., eggs incubated in the sand wetted with water (Fig. 8A, B, GLMM, p $<0.001$ each). The hatching rate was significantly lower for the eggs treated with the frass extracts from migratory locusts than for those treated with the frass extracts from Bombay locusts (GLMM, p < 0.001), whereas no significant difference was observed between the two controls $(\mathrm{GLMM}, \mathrm{p}=0.96)$.

Effect of water extract of rescue grass-fed desert locust frass on embryonic development. - For the desert locust control eggs, the maximum egg widths on days one to three were similar (Fig. 9A; ANOVA, $F=1.67, \mathrm{df}=2,27, \mathrm{p}=0.21$ ), and maximum egg widths increased significantly on day four compared with day three $(\mathrm{t}=$ $-10.49, \mathrm{df}=18, \mathrm{p}<0.001)$. The maximum egg width leveled off from day eight onward. In contrast, the maximum width of eggs incubated in the sand treated with the frass extract on day three increased slightly on day four (Tukey's multiple comparison, p $<0.05$ ) but showed no further increase (Tukey's multiple comparison, $\mathrm{p}>0.05$ ). 
(A) (14)

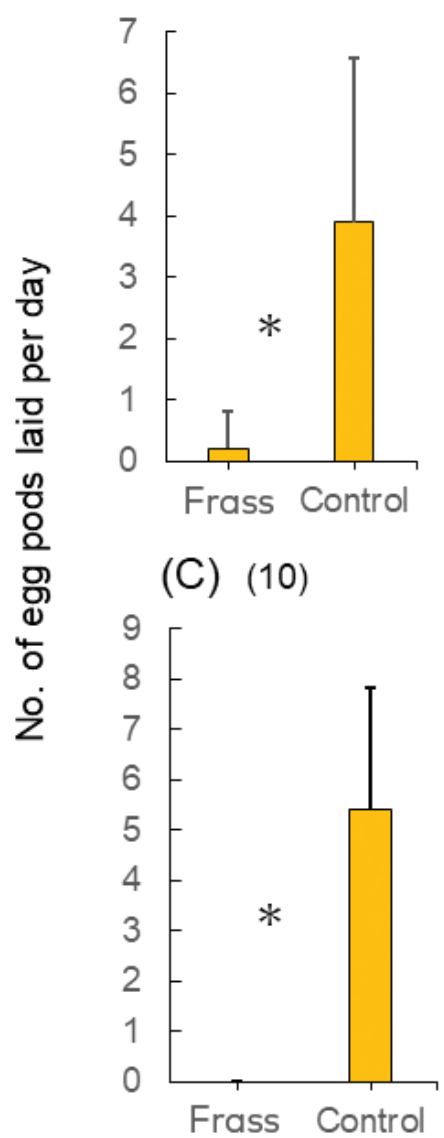

(B) (14)

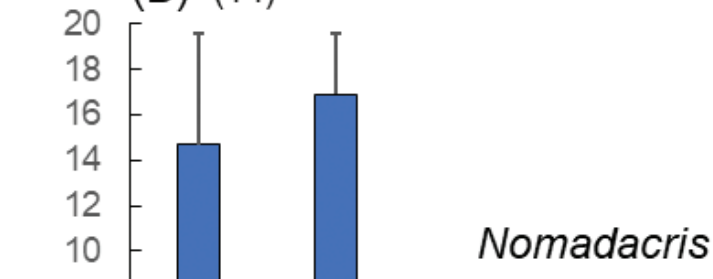

\section{Locusta}

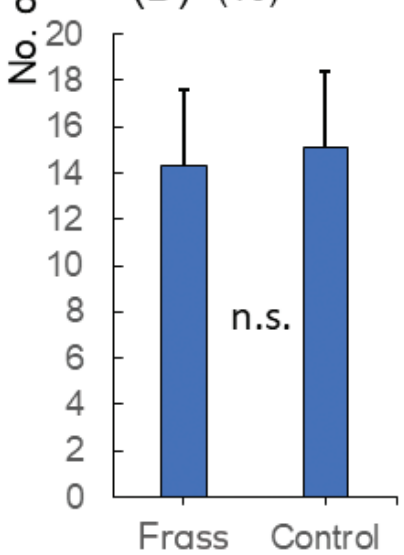

Fig. 5. Effects of water extracts of frass produced by A, B. Bombay locusts and C, D. Migratory locusts fed with rescue grass leaves on the numbers of egg pods laid $(\mathrm{A}, \mathrm{C})$ and holes dug $(\mathrm{B}, \mathrm{D})$ by adult female desert locusts presented with extracts mixed with sand. Two cups containing frass extract (treated) and water (control) were simultaneously presented to locusts in each of two locust cages, and the data were combined. Numbers in parentheses indicate the total numbers of days observed. Bars on histograms indicate one standard deviation. Asterisks indicate significant differences at the $5 \%$ level with a t-test. n.s. indicates no significant difference.

Table 1. Effects of water extracts of desert locust frass fed with various plants (A-G) and water extracts of those plants (H-M) on egg hatching rates. Five or three groups of 20 eggs were buried in sand wetted with each extract and water alone (control) within three days after oviposition and were observed for hatching at $30^{\circ} \mathrm{C}$. Comparisons with controls were made with GLMM. Frass collected under two umbrella thorn trees in 2016 and 2017 were designated as AT \#1 and AT \#2. LS, Lactuca sativa var. longifolia (romaine lettuce); DG, Dactylis glomerata (orchard grass); SB, Sorghum bicolor (sorghum); MS, Miscanthus sinensis (silver grass); BR, Brassica rapa var. perviridis (Japanese mustard spinach); BO, Brassica oleracea var. capitata (cabbage).

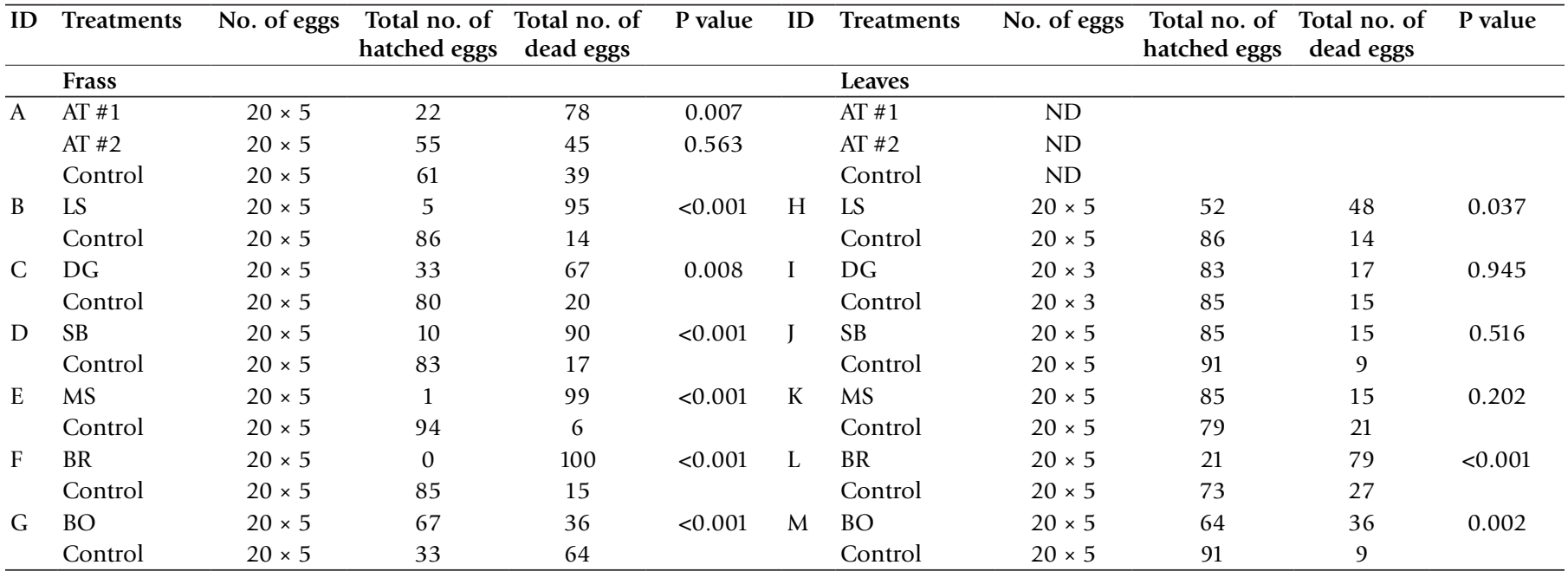




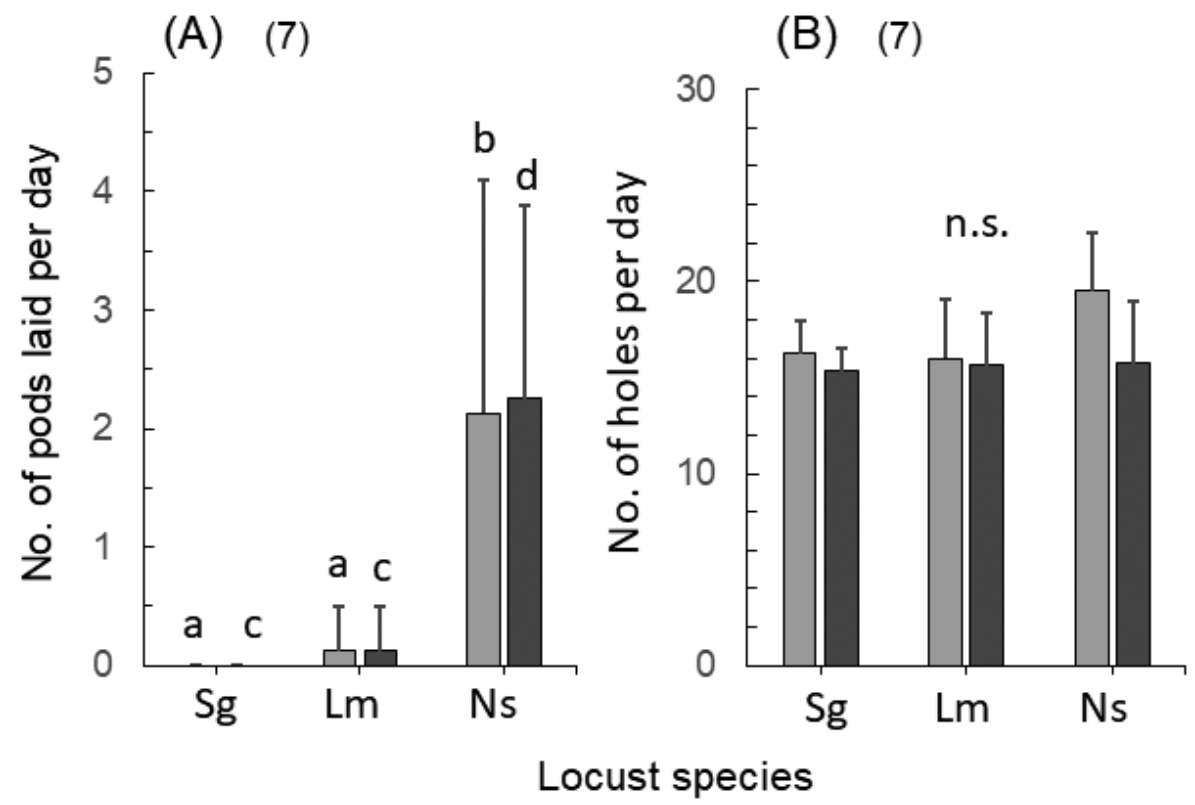

Fig. 6. Effects of water extracts of frass produced by desert locusts (Sg), migratory locusts (Lm), and Bombay locusts (Ns) fed with rescue grass leaves on the number of $\mathbf{A}$. Egg pods and B. Holes dug by adult desert locusts presented with extracts mixed with sand. Three cups containing frass extracts of the three locust species were simultaneously presented to locusts in each of two locust cages (light and dark histograms) for seven days. Numbers in parentheses indicate the total numbers of days observed. Bars on histograms indicate one standard deviation. Different letters in each comparison (light or dark histograms) in (A) indicate significant differences at the 5\% level with Tukey's multiple comparison test. n.s. indicates no significant differences in each comparison with ANOVA (light or dark histograms).
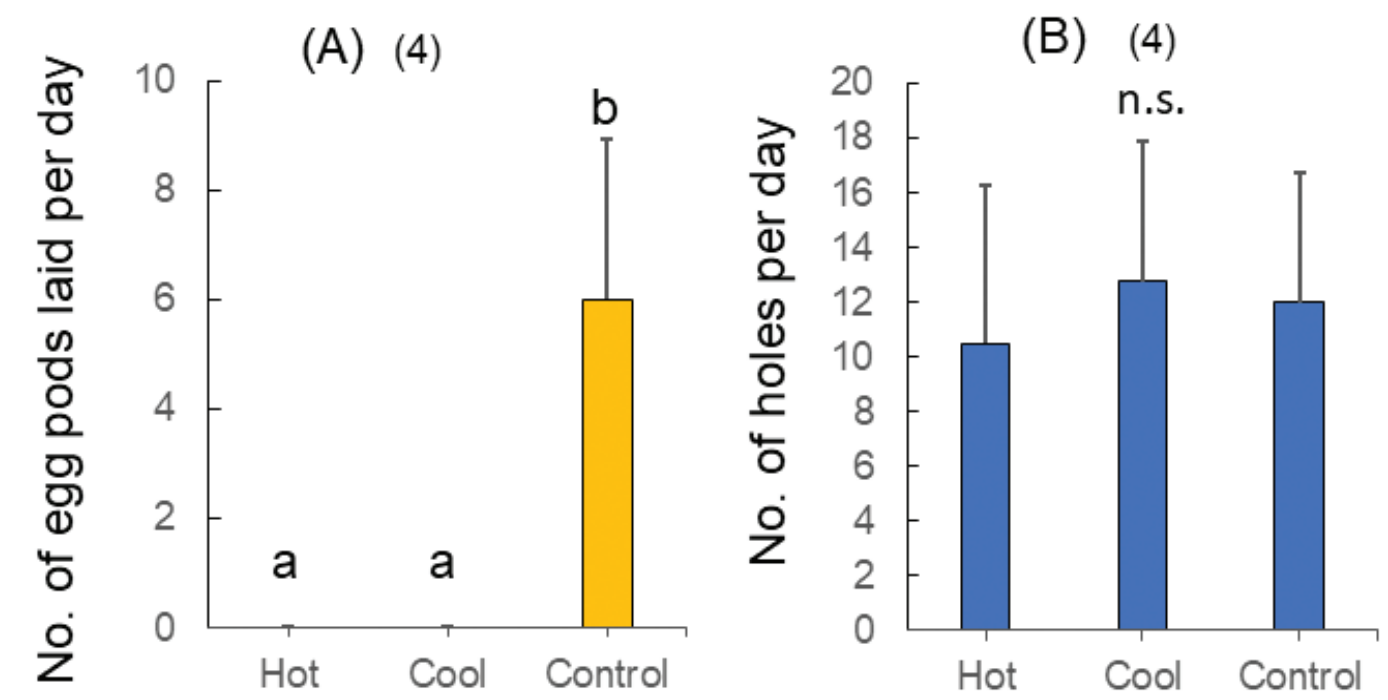

Fig. 7. Effects of hot and cool water extracts of rescue grass-fed desert locust frass on the number of A. Egg pods laid and B. Holes dug by adult female desert locusts. Frass were extracted with boiling and cool water and the extracts were mixed with sand. Sand cups containing these extracts and water as a control were presented to locusts in the same cage for 4 days. Numbers in parentheses indicate the total numbers of days observed. Bars on histograms indicate one standard deviation. Different letters in (A) indicate significant differences at the 5\% level with Tukey's multiple comparison test. n.s. in (B) indicates no significant difference with ANOVA at the 5\% level.

The mean antennal length $( \pm \mathrm{SD})$ for the control embryos on day three was $0.16 \pm 0.04 \mathrm{~mm}(\mathrm{n}=10)$, increased to $2.48 \pm 0.27$ $\mathrm{mm}$ by day 13, and subsequently leveled off.

In contrast, the embryos treated with the frass extract slightly increased their antennal length by day five, but no further elongation was observed through day 11 when the eggs darkened and some contained only amorphous embryos (Fig. 9B; ANOVA, F =
$7.65, \mathrm{df}=4,33, \mathrm{p}=0.07)$. The difference in the mean values of the two groups became significant from day seven onward (t-test, $\mathrm{p}<0.001$ each). Examples showing embryos on days five and nine are shown in Fig. 9C-F. The embryos treated with the frass extract reached stage VI-VII, according to the embryonic stages described for desert locusts by Shulov and Pener (1963) and were deformed (Fig. 9F). 
(A)

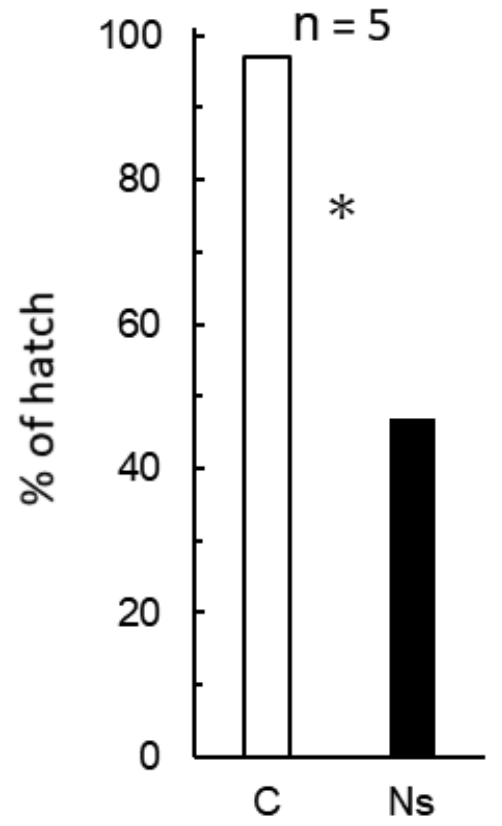

(B)

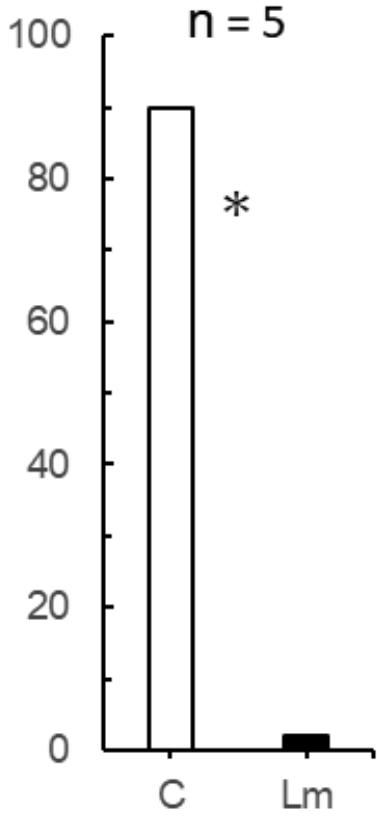

Fig. 8. Effects of water extracts of rescue grass-fed Bombay locust (Ns) and migratory locust (Lm) frass on desert locust egg hatching rates. Five groups of 20 eggs were buried in sand wetted with each extract and water alone (control, C) within three days after oviposition and were observed for hatching at $30^{\circ} \mathrm{C}$. Asterisks indicate significant differences at the 5\% level with GLMM.

The incubation of eggs in the sand treated with frass extract and water alone, respectively, on day seven onward showed no significant difference on day 13 (the day before hatching) for either egg widths $(\mathrm{t}=1.56, \mathrm{df}=18, \mathrm{p}=0.14$; data not shown $)$ or antennal lengths $(\mathrm{t}=0.823, \mathrm{df}=10, \mathrm{p}=0.43$; Suppl. material 3: Fig. S3). However, the hatching rate was significantly lower in the eggs treated with the frass extract $(41.7 \%, \mathrm{n}=60)$ than in the controls $(90.0 \%, \mathrm{n}=60, \mathrm{GLMM}, \mathrm{p}<0.001)$, indicating that mortality occurred after embryogenesis was completed.

\section{Discussion}

Locusts ready to lay eggs must find a suitable site for oviposition. The ovipositing behavior consists of digging and laying eggs (Uvarov 1977). Locusts search and probe for a suitable site by using olfactory and visual signals in the environment. Norris (1968) reported that adult female desert locusts avoided laying eggs close to plants when placed in a cage $152 \mathrm{~cm}$ long with fresh grass at one end of the cage and without grass at the other end. Dry grass and alcohol extracts of grass also had a significant oviposition repellent effect. However, it is unknown whether this repellent effect of grass is exerted on the digging behavior, egg laying behavior, or both, because the number of digs was not described. Norris (1968) also demonstrated that more eggs were laid close to straw-colored raffia than to green raffia, indicating the involvement of a visual factor in oviposition behavior. In the present study, cups with visually similar sand surfaces were presented to locusts. As such, the differences observed in oviposition activity were unlikely to be visually influenced.

Locusts may dig holes in the soil but do not necessarily lay eggs (Norris 1963). One female desert locust was observed dig-

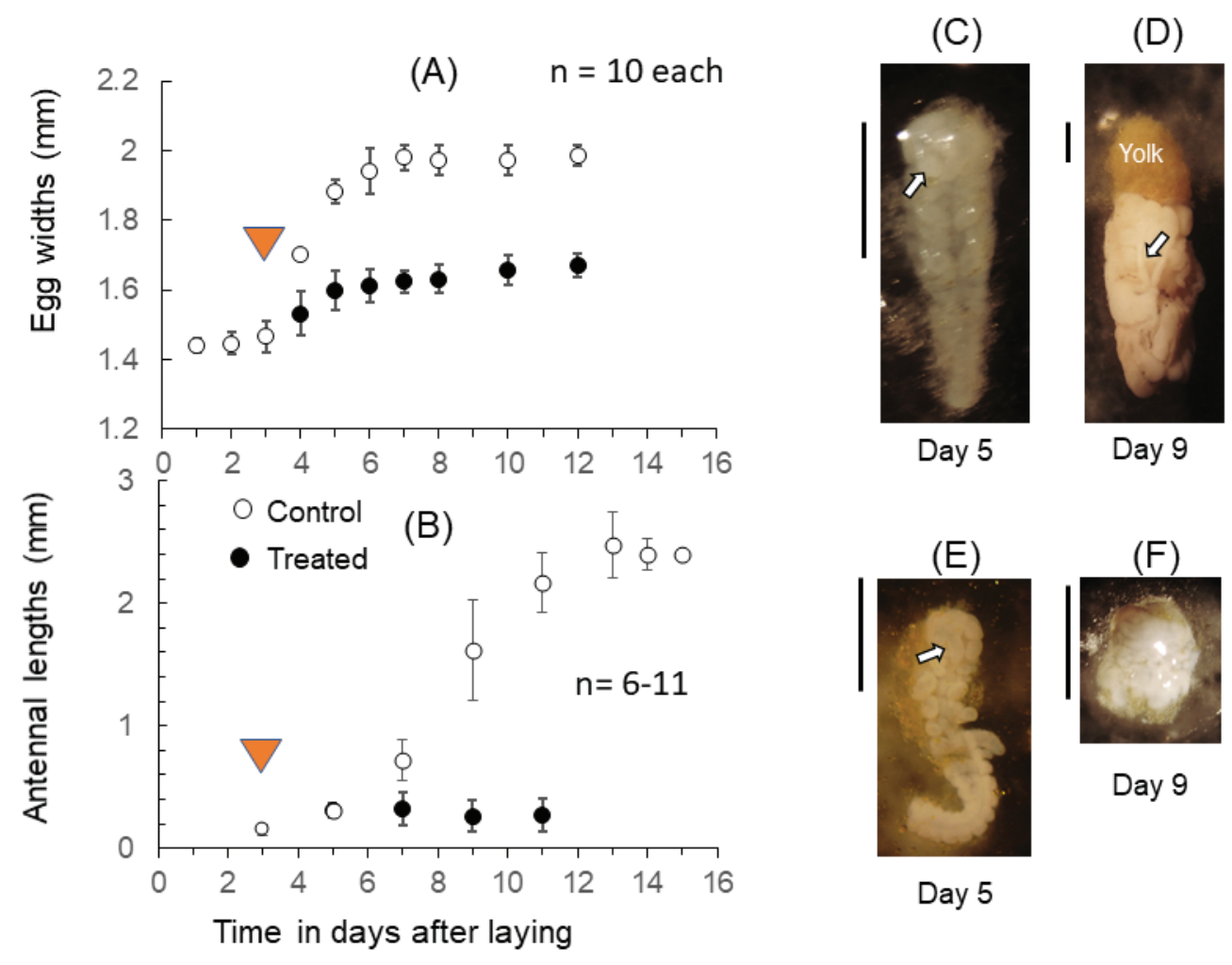

Fig. 9. Effects of water extracts of rescue grass-fed desert locust frass on A. Egg widths (mean \pm SD; $n=10)$ and $\mathbf{B}$. Antennal lengths of embryos (mean $\pm S D ; n=6-11$ ). Eggs were incubated in sand wetted with the frass extract (treated) or water (control) on day three after oviposition at $30^{\circ} \mathrm{C}$. C-F. Photographs show embryos observed on days 5 and 9 . Triangles in (A) and (B) indicate the time when the treatment started. Vertical bars in $\mathbf{C}-\mathbf{F}$ indicate $1 \mathrm{~mm}$. White arrows indicate an embryonic antenna in $\mathbf{C}-\mathbf{E}$. 
ging up to 32 holes before laying an egg pod (Norris 1968). In our laboratory, one female desert locust was observed to dig as many as 18 holes in a sand cup for $24 \mathrm{~h}$ without laying any eggs (Tanaka, S. unpublished observation). Therefore, the number of holes observed in the present study may only indicate that at least some female adults were actively engaged in oviposition behavior.

It has been reported that frass of desert locusts fed with rescue grass contain a water-soluble factor that inhibits oviposition (Tanaka and Sugahara 2017). Rescue grass has its origin in South America and was introduced to a wide range of temperate, subtropical, and tropical countries (Verloove 2012). Therefore, it remains unknown whether similar OI effects are also present in locust frass produced in the wild. The present study demonstrates that frass of wild desert locusts, collected under umbrella thorn trees in the Mauritanian desert, also exerted an OI effect. In Tunisia, romaine lettuce is a crop grown outdoors where desert locusts can feed on it. Frass collected from locusts fed with this plant in the laboratory in Tunisia were also observed to exert an OI effect. This observation was confirmed with adult desert locusts fed the same plant grown in Japan (Fig. 3D; Suppl. materials 1,2: Figs S1D and S2D).

In the present study, five other plants (i.e., in addition to rescue grass) were separately fed to adult desert locusts, and the produced frass and leaves of each plant were tested for the OI effect by simultaneously presenting three sand cups containing extracts of the frass, extracts of the leaves, and only water (as a control) to locusts. The results were similar in all the plant species tested; few or no egg pods were laid in the sand cups containing frass and leaf extracts, and most or all egg pods were laid in the control cups. Similar results were observed when these extracts were separately presented to locusts with a control sand cup (Suppl. materials 1,2: Figs S1 and S2). When sand cups containing leaf and frass extracts were simultaneously presented to locusts with no control sand cup, oviposition activity was generally low, although a high rate of digging activity was observed. In general, more egg pods were laid in sand cups containing leaf extracts than those containing frass extracts, indicating that the OI effect of the frass extracts was greater than that of the leaf extracts.

The OI effect was also observed in extracts of frass obtained from two other locust species, i.e., Bombay locusts and migratory locusts, when tested on desert locusts. Water extracts of frass produced by both locust species fed with rescue grass almost completely inhibited oviposition by desert locusts. Among the water extracts made with frass obtained from the three locust species, those from desert locusts had the greatest OI effect, followed by those from migratory locusts and Bombay locusts when tested against adult desert locusts, although the difference between the first two was not statistically significant. In contrast, the number of holes dug was similar among the three extracts, indicating that the frass extracts did not differentially affect digging behavior in desert locusts.

Tanaka and Sugahara (2017) reported that the OI factor contained in frass was heat-stable. Although they heated the filtrated solution immediately after extraction with water, there is the possibility that bacterial activity was involved in the production of the active compound(s) during extraction. The present study tested this possibility by extracting frass with boiling water and mixing the filtrated solution with sterilized sand. The results showed that OI effects of hot water extracts were as strong as those of cool water extracts, indicating that the OI factor was not produced by bacteria during the extraction process.

As observed for the frass produced by desert locusts fed with rescue grass in a previous study (Tanaka and Sugahara 2017), the frass extracts obtained from desert locusts that were fed with five other plant species in the laboratory significantly reduced egg hatching rates when mixed with sand and used to incubate eggs. One of the frass samples collected under umbrella thorn trees also had a similar effect, but the other sample did not. This difference might have been related to the stability of the active compounds, as it is not known how long the frass had remained on the sand surface in the desert before collection. The difference in the lethal effects on eggs between the two frass samples might indicate that the active compounds affecting egg hatching rates and those affecting oviposition activity are different. This hypothesis should be tested in the future.

The water extracts of rescue grass leaves do not affect egg hatching rates (Tanaka and Sugahara 2017). Similar results were obtained for orchard grass, silver grass, and sorghum in the present study. However, significant effects on egg hatching rates were observed for leaves of romaine lettuce and the two cruciferous species, Japanese mustard spinach and cabbage. The differences in the lethal effects on eggs among different plants are not easy to interpret. However, these results suggest that the active compounds are present only in some specific plants. Alternatively, the results might represent differences in the amounts of active compounds contained in the plants or different elution efficiencies of the active compounds from leaves of different plants. Identification of the active compounds present in these plant species and frass produced by locusts will help address this problem.

The frass extracts of rescue grass-fed desert locusts suppressed embryonic development when the eggs were incubated with sand mixed with the extracts three days after oviposition. All treated embryos remained in the anatrepsis stage, which is the stage before the embryo rotates inside the eggshell (Shulov and Pener 1963). Water absorption that occurred during days three to seven in the control eggs was also inhibited by the frass extract, which was likely to be related to the suppressed embryonic development. The lethal effect was observed even when the eggs were treated with frass extracts during the second half of embryonic development (Tanaka and Sugahara 2017). This was confirmed in the present study, as seven-day-old embryos had reduced hatching rates, but there were no apparent morphological abnormalities after incubation in the sand containing frass extracts. Therefore, the frass extracts apparently exerted effects on locust embryos at different stages in different ways.

The ecological significance of the behavioral and developmental responses of $S$. gregaria to frass and leaf extracts observed in the present study is not clear. Although this phenomenon should be confirmed using wild locusts or a recently established laboratory colony, we observed similar OI effects of frass extracts in another laboratory strain derived from Ethiopia and in another locust, $L$. migratoria (Tanaka, S. unpublished observation). Therefore, the present results were not specific to the laboratory strain used. Stower et al. (1958) observed that desert locusts laid eggs at some distance from plants in the field. It is not clear whether this pattern was a result of the effects of plants on the probing, egg laying, or both behaviors of locusts. However, an area close to host plants may have a high probability of being covered with frass or leaves and the habit of avoiding laying eggs close to plants might have evolved due to their inhibitory effects on locust embryos. Some host plants of desert locusts in the desert contain toxic compounds such as alkaloids (Simões et al. 2016). It would be interesting to examine how such plants or frass produced by locusts fed these plants affect oviposition and egg survival because information obtained from such observations might provide insights into the development of a new control measure against this notorious pest insect.

In conclusion, inhibitory effects on oviposition and embryonic development in desert locusts were observed not only for the frass 
produced by laboratory-reared locusts, but also for the frass produced by locusts in the wild. The locust frass and leaves of seven plants tested so far, including rescue grass (Tanaka and Sugahara 2017), consistently exerted great OI effects. In general, the extracts of the frass had higher inhibitory effects on embryonic development than extracts of the leaves of the plants. The OI effects were also detected in the frass produced by migratory locusts and Bombay locusts when tested on desert locusts, suggesting the possibility that some common biologically active compounds are contained in their frass.

\section{Acknowledgements}

We thank Ms. Utako Takano, Mr. Shoichi Enoki, Ms. Hiroko Ikeda, and Dr. Ryohei Sugahara (NIASO and NARO) for their cooperation and assistance with rearing the locusts. We would like to thank Mr. Kameo Tsukada and Mr. Hirokazu Tomiyama (Field Management Section of NIASO and NARO) for growing the grass.

\section{References}

Brader L, Djubo H, Faye FG, Ghaout S, Lazar M, Ngyala PM, Babah MA (2006) Towards a more effective response to desert locusts and their impacts on food insecurity, livelihoods and poverty. Independent Multilateral Evaluation of the 2003-05 Desert Locust Campaign -FAO, Rome, 113pp.

Ji R, Xie B-Y, Li D-M, Li Z, Zeng X-C (2007) Relationships between spatial pattern of Locusta migratoria manilensis eggpods and soil property variability in coastal areas. Soil Biology and Biochemistry 39: 18651869. https://doi.org/10.1016/j.soilbio.2007.01.016

Newland P, Yates P (2008) The role of contact chemoreception in egg-laying behaviour of locusts. Journal of Insect Physiology 54: 273-285. https://doi.org/10.1016/j.jinsphys.2007.09.011

Norris MJ (1963) Laboratory experiments on gregarious behaviour and ovipositing females of the desert locust (Schistocerca gregaria (Fork.)). Entomologia Experimentalis et Applicata 6: 279-303. https://doi. org/10.1111/j.1570-7458.1963.tb00628.x

Norris MJ (1968) Laboratory experiments on oviposition responses of the desert locust, Schistocerca gregaria (Forsk.) Anti-locust Bulletin 43: 1-43.

Pener MP (1991) Locust phase polymorphism and its endocrine relations. Advances in Insect Physiology 23: 1-79. https://doi.org/10.1016/ S0065-2806(08)60091-0

Pener MP, Simpson SJ (2009) Locust phase polyphenism: An update. Advances in Insect Physiology 36: 1-272. https://doi.org/10.1016/ S0065-2806(08)36001-9

R Core Team (2018) R: A language and environment for statistical computing. Version 3.4.2. R Foundation for Statistical Computing, Vienna.

Shulov A, Pener MP (1963) Studies on the development of the desert locust (Schistocerca gregaria Forskål) and its interruption under particular conditions of humidity. Anti-locust Bulletin 41: 1-59.

Simões PMV, Ott SR, Niven JE (2016) Environmental adaptation, phenotypic plasticity and associative learning in insects: The desert locust as case study. Integrative and Comparative Biology 56: 914-924. https:// doi.org/10.1093/icb/icw100

Stower WJ, Popov GB, Greathead DJ (1958) Oviposition behaviour and egg mortality of the desert locust, Schistocerca gregaria (Forsk.). Antilocust Bulletin 30: 1-33.

Tanaka S, Sugahara R (2017) Desert locusts Schistocerca gregaria (Acrididae: Orthoptera) do not lay eggs in old sand: Why? Applied Entomology and Zoology 52: 635-642.

Uvarov B (1966) Grasshoppers and Locusts: A handbook of general acridology. Vol. 1. Anatomy, physiology, development, phase polymorphism, introduction to taxonomy. Cambridge University Press, Cambridge, 481 pp.

Uvarov B (1977) Grasshoppers and Locusts: A handbook of general acridology. In: Behaviour, Ecology, Biogeography, Population Dynamics. Vol. 2. Overseas Pest Research, London, 613 pp.

Verloove F (2012) A revision of Bromus section Ceratochloa (Pooideae, Poaceae) in Belgium. Dumortiera 101: 30-45.
Woodman JD (2017) Effects of substrate salinity on oviposition, embryonic development and survival in the Australian plague locust, Chortoicetes terminifera (Walker). Journal of Insect Physiology 96: 9-13. https://doi.org/10.1016/j.jinsphys.2016.10.001

Woodrow DF (1965a) The responses of the African migratory locust, Locusta migratoria migratorioides R. \& F. to the chemical composition of the soil at oviposition. Animal Behaviour 13: 348-356. https://doi. org/10.1016/0003-3472(65)90056-4

Woodrow DF (1965b) Laboratory analysis of oviposition behaviour in the Red Locust, Nomadacris septemfasciata (Serv.). Bulletin of Entomological Research 55: 733-745. https://doi.org/10.1017/S0007485300049841

\section{Supplementary material 1}

Author: Seiji Tanaka, Toyomi Kotaki, Yudai Nishide, Amel BenHamouda, Khemais Abdellaoui, Mohamed Abdallahi Bahah Ebbe, Sidi Ould Ely

Data type: multimedia

Explanation note: Fig. S1. Effects of water extracts of desert locust frass after feeding on various plants on the numbers of egg pods laid when adult female desert locusts were presented with extracts mixed with sand.

Copyright notice: This dataset is made available under the Open Database License (http://opendatacommons.org/licenses/ odbl/1.0/). The Open Database License (ODbL) is a license agreement intended to allow users to freely share, modify, and use this Dataset while maintaining this same freedom for others, provided that the original source and author(s) are credited.

Link: https://doi.org/10.3897/jor.26.34665.suppl1

\section{Supplementary material 2}

Author: Seiji Tanaka, Toyomi Kotaki, Yudai Nishide, Amel BenHamouda, Khemais Abdellaoui, Mohamed Abdallahi Bahah Ebbe, Sidi Ould Ely

Data type: multimedia

Explanation note: Fig. S2. Effects of water extracts of leaves of various plants on the numbers of egg pods laid when presented to adult female desert locusts mixed with sand.

Copyright notice: This dataset is made available under the Open Database License (http://opendatacommons.org/licenses/ odbl/1.0/). The Open Database License (ODbL) is a license agreement intended to allow users to freely share, modify, and use this Dataset while maintaining this same freedom for others, provided that the original source and author(s) are credited.

Link: https://doi.org/10.3897/jor.26.34665.suppl2

\section{Supplementary material 3}

Author: Seiji Tanaka, Toyomi Kotaki, Yudai Nishide, Amel BenHamouda, Khemais Abdellaoui, Mohamed Abdallahi Bahah Ebbe, Sidi Ould Ely

Data type: multimedia

Explanation note: Fig. S3. Effects of water extracts of rescue grassfed desert locust frass on antennal lengths of embryos (A, mean $\pm \mathrm{SD} ; \mathrm{n}=6-10)$.

Copyright notice: This dataset is made available under the Open Database License (http://opendatacommons.org/licenses/ odbl/1.0/). The Open Database License (ODbL) is a license agreement intended to allow users to freely share, modify, and use this Dataset while maintaining this same freedom for others, provided that the original source and author(s) are credited.

Link: https://doi.org/10.3897/jor.26.34665.suppl3 